\title{
Assessment of a Geothermal Combined System with an Organic Rankine Cycle and Multi-effect Distillation Desalination
}

\author{
Aida Farsi ${ }^{1}$ (D) Marc A. Rosen ${ }^{1}$ \\ Received: 14 July 2021 / Revised: 28 October 2021 / Accepted: 30 October 2021 / Published online: 1 January 2022 \\ (C) The Author(s) 2021
}

\begin{abstract}
An analysis is reported of a geothermal-based electricity-freshwater system in which an organic Rankine cycle is integrated with a multi-effect distillation desalination unit. The system is driven by geothermal hot water extracted from the production well. Mass, energy, entropy, and exergy rate balances are written for all system components, as are energy and exergy efficiency expressions for each subsystem. The exergy destruction rate associated with the temperature and chemical disequilibrium of the freshwater and brine with the reference environment are taken into account to reveal accurate results for irreversibility sources within the desalination process. The developed thermodynamic model is simulated using thermodynamic properties of the working fluids (i.e., ammonia, seawater, distillate, and brine) at each state point. A sustainability analysis is performed that connects exergy and environmental impact concepts. That assessment expresses the extent of the contribution of the system to sustainable development and reduced environmental impact, using exergy methods. Results of the sustainability analysis indicate that, with an increase in the reference environment temperature from 20 to $35^{\circ} \mathrm{C}$, the exergy destruction rate decreases for the multi-effect distillation and organic Rankine cycle systems respectively from 6474 to $4217 \mathrm{~kW}$ and from 16,270 to $13,459 \mathrm{~kW}$. Also, the corresponding sustainability index for the multi-effect distillation and organic Rankine cycle systems increases from 1.16 to 1.2 and 1.5-1.6, respectively, for the same increase in reference environment temperature.
\end{abstract}

Keywords Geothermal · Organic Rankine cycle $\cdot$ Multi-effect distillation $\cdot$ Desalination · Energy $\cdot$ Exergy $\cdot$ Sustainability

$\begin{array}{ll}\text { List of Symbols } \\ \\ B P E & \text { Boiling point elevation }\left({ }^{\circ} \mathrm{C}, \mathrm{K}\right) \\ \dot{m} & \text { Mass flow rate }(\mathrm{kg} / \mathrm{s}) \\ e x & \text { Specific exergy }(\mathrm{kJ} / \mathrm{kg}) \\ \dot{E x} & \text { Exergy rate }(\mathrm{kW}) \\ \dot{E x} & \text { Exergy destruction rate }(\mathrm{kW}) \\ h & \text { Specific enthalpy }(\mathrm{kJ} / \mathrm{kg}) \\ h_{f g} & \text { Latent heat }(\mathrm{kJ} / \mathrm{kg}) \\ P & \text { Pressure }(\mathrm{kPa}) \\ \dot{Q} & \text { Heat transfer rate }(\mathrm{kW}) \\ s & \text { Specific entropy }(\mathrm{kJ} / \mathrm{kg} . \mathrm{K})\end{array}$

Aida Farsi

aida.farsi@ontariotechu.net

Marc A. Rosen

marc.rosen@ontariotechu.ca

1 Faculty of Engineering and Applied Science, University of Ontario Institute of Technology, 2000 Simcoe Street North, Oshawa, ON L1G 0C5, Canada

$\begin{array}{ll}S I & \text { Sustainability index } \\ T & \text { Temperature }\left({ }^{\circ} \mathrm{C}, \mathrm{K}\right) \\ T B T & \text { Top brine temperature }\left({ }^{\circ} \mathrm{C}, \mathrm{K}\right) \\ \dot{W} & \text { Work rate }(\mathrm{kW}) \\ w & \text { Salinity }(\mathrm{kg} / \mathrm{kg} \\ \text { Greek } & \text { letters } \\ \eta & \text { Efficiency } \\ \rho & \text { Density }\left(\mathrm{kg} / \mathrm{m}^{3}\right) \\ \Psi & \text { Exergy efficiency } \\ \mu & \text { Chemical potential }(\mathrm{kJ} / \mathrm{kg} \\ \text { Subscripts } \\ 0 & \text { Reference state } \\ B & \text { Brine } \\ c h & \text { Chemical } \\ c w & \text { Cooling water } \\ \text { cond } & \text { Condensation, condenser } \\ D & \text { Distillate } \\ \text { Des } & \text { Destruction } \\ \text { exp } & \text { Expander }\end{array}$




$\begin{array}{ll}f & \text { Feed } \\ p h & \text { Physical } \\ \text { sep } & \text { Separator } \\ \text { SG } & \text { Steam generator } \\ \text { sw } & \text { Seawater }\end{array}$

\section{Introduction}

Increasing freshwater demands in irrigation, industrial, and municipal sectors have placed significant stresses on available freshwater supply options like rivers, lakes, and aquifers to satisfy the global need for freshwater. To address this issue, seawater desalination technologies have received much attention around the world, especially in arid regions. Urbanization, population growth, and industrialization have been key drivers in recent years of the need for desalination technologies. Desalination systems are typically driven by heat and/or work, and they are reliable techniques for producing freshwater from low-quality water resources.

Fossil fuels often use for providing the energy required for desalination systems. This raises additional concerns about the environmental impacts of desalination plants. The use of renewable energy resources like geothermal energy, for desalination and other uses, is growing in importance in many countries. It is suggested that the integration of renewable energy resources with technologies for recovery, reuse, and recycling of energy and water can provide a sustainable and environmentally beneficial approach to meeting water and energy needs.

Geothermal energy is a reliable, sustainable, and costeffective renewable energy resource in which water and/ or steam carry the geothermal heat to the surface of Earth. Some important advantages of geothermal energy resources are their independence from weather conditions, high capacity factors, and consistent heat production rates (unlike intermittent energy sources like solar and wind). Geothermal energy sources can be used for heating, cooling, and electricity generation. For electricity generation applications, medium- or high-temperature geothermal resource are normally required; these are usually located near tectonically active regions.

There are several stages in developing geothermal power systems including exploration, drilling, plant/reservoir development, and electrical power generation. The range and scale of geothermal systems for domestic, agricultural, and industrial sectors have expanded with recent advances in geothermal technologies.

Geothermal energy provides a low-emission technique for electrical power generation. Hot water or dry steam with temperatures typically ranging from 80 to $150{ }^{\circ} \mathrm{C}$ is extracted from drilled wells and transferred to the power plant (Bundschuh et al. 2015). In the power plant, the temperature at the first or second pass of the steam turbine is still high enough to drive a low-temperature desalination system like multi-effect distillation (MED) desalination or membrane desalination.

In some geothermal desalination systems, hot water or dry steam can be used directly to generate freshwater, while electricity is produced first and then used in the desalination systems in others. Dual- and multi-generation systems are other types of geothermal-based systems in which geothermal energy, in combination with other renewable energy resources, is used to drive desalination and other energy systems.

A pilot MED desalination system driven by geothermal heat was constructed at Kimolos Island, Greece (Fytikas et al. 2005; Karytsas et al. 2002). The temperature of the geothermal energy source is $61^{\circ} \mathrm{C}$; it drives the MED system which has a freshwater production rate of $75 \mathrm{~m}^{3} / \mathrm{h}$. Karytsas et al. (2002) showed that employing low/medium-temperature geothermal heat can potentially offset the consumption of 453,600 kg of oil per year. Another geothermal-based MED plant was built at Texas, with an average freshwater production rate of $120 \mathrm{~m}^{3} /$ day (Birney et al. 2019). The maximum underground temperature in Texas is about $150{ }^{\circ} \mathrm{C}$ at the depths of 3000-4000 m. Birney et al. (2019) showed that, as the geothermal fluid mass flow rate increases from 30 to $90 \mathrm{~kg} / \mathrm{s}$, the freshwater production rate in the geothermal MED system increases from 121 to $1132 \mathrm{~m}^{3} /$ day.

Missimer et al. (2014) proposed a geothermal-based power cycle and desalination pilot plant for the cogeneration of electricity and freshwater. High-temperature steam (about $300^{\circ} \mathrm{C}$ ) at a pressure of $6-7 \mathrm{MPa}$ is extracted from the production well to drive the steam turbine in the system. A part of the electricity produced by the steam turbine is used to drive a reverse osmosis desalination system. The turbine outlet steam is also utilized to operate MED and membrane desalination systems. Petrovic et al. (2018) studied thermodynamically an MED desalination plant linked to hot springs combined with ejector refrigeration. Optimization studies for the system were carried out to minimize the total investment costs and total exergy loss rate and to maximize plant profits. In addition, various refrigerants for the refrigeration system were compared in terms of system performance and cost.

Musharavati et al. (2021) proposed a geothermal-based poly-generation system in which a Kalina cycle, reverse osmosis unit, PEM electrolyzer, and thermoelectric module are used to produce electricity, hydrogen, and freshwater production. A thermodynamic model is developed for the system and assessed using exergy analysis for different system locations. It was shown that the condenser and reverse osmosis unit have the greatest exergy destruction rates among all system components. Also, a multi-objective optimization is performed for the system to find the 
optimum exergy destruction rate, exergy destruction cost rate, and electricity cost rate. The optimum values of exergy destruction rate, exergy destruction cost rate, and electricity cost rate, respectively, were found to be $328.2 \mathrm{~kW}, 18.4 \$ / \mathrm{h}$, and $12.83 \$ / \mathrm{h}$.

Many advances in sustainable energy and desalination technologies have been reported in recent years. Renewable energy systems and their applications have been reviewed extensively (Ahmadi et al. 2020; Nassrullah et al. 2020; Panagopoulos 2021; Vaithilingam et al. 2020). More broadly, Kilkis et al. (2020) and Rezaie and Rosen (2020) investigated the importance of water systems and their integration with energy and environment systems. Specific studies have been undertaken on solar desalination systems (Aboelmaaref et al. 2020; Tong et al., 2020), photovoltaics (Anand et al. 2021; Wu et al. 2021), high-temperature geothermal energy (Abdolalipouradl et al. 2020; Farsi and Dincer 2019; Gnaifaid and Ozcan 2021), ambient ground energy sources (Rosen and Koohi-Fayegh 2017; Alavy et al. 2021), solar ponds (Kasaeian et al. 2018; Mosaffa and Farshi 2021), and nuclear energy (Khan et al. 2017; Ghazaie et al. 2020; Marques et al. 2020). Technologies have also received attention that facilitate the use of sustainable energy, like energy storage (Cuce et al. 2020; Campione et al. 2020; KoohiFayegh and Rosen 2020; Dincer and Rosen 2021a), cogeneration, and district energy (Rosen and Koohi-Fayegh 2016).

The thermodynamics of geothermal-based energy systems is important for determining their behaviors and efficiencies. Thermodynamic models of geothermal electricityfreshwater combined systems can reveal particularly useful insights into their behaviors. Energy and exergy methods can be applied to such systems to determine the thermodynamic properties of all streams interacting with and within the system. This study introduces a new geothermal-based electricity-freshwater combined system in which the geothermal hot water drives an organic Rankine cycle (ORC) and multi-effect distillation system. The objective is to develop an understanding of the system and its performance, to facilitate potential adoption in the future.

One of the effective ways to reduce the environmental impacts of energy systems is to reduce their exergy destructions and losses. These can be reduced by increasing the exergy efficiencies of energy systems. In this paper, two energy systems, an organic Rankine cycle and an MED desalination system, are combined and driven by a geothermal energy resource. It is shown that integration of the ORC and MED systems potentially improves the exergy efficiency, and reduces the exergy destruction rate and consequently environmental impacts. For this purpose, mass, energy, entropy, and exergy rate balances are developed for each component of the geothermal combined electricity-freshwater system. Then, the energy-based performances of the ORC and MED system are determined, as are the exergy-based performances in terms of exergy efficiencies. Finally, a sustainability analysis is performed to show how exergy methods assist in understanding renewable energy technologies and in making energy utilization more efficient and less likely to cause environmental impacts. By this analysis, relations between exergy efficiency, environmental impact, and sustainability for the combined system are investigated.

\section{System Description}

Figure 1 shows the combined electricity-freshwater generation system in which an organic Rankine cycle is integrated with a parallel-feed multi-effect distillation desalination system. The ORC system is comprised of a boiler, expander, condenser, and pump. Ammonia is used as the working fluid in the ORC system. The hot hydrothermal fluid extracted from geothermal production well enters the boiler then passes to the steam generator to produce steam for the MED desalination system. The energy in the hydrothermal fluid leaving the steam generator can be further used in moderate-temperature applications like heating water for fish farming or domestic usage. The fluid is then is transferred back to the re-injection well. In the ORC system, superheated ammonia expands in the expander and produces electricity. Then, it cools in the condenser and is pumped to the boiler. The MED system includes six effects. The intake seawater is preheated before entering the effects. Cooling water is used to control the feed temperature to the MED system. Design parameters for the combined system are given in Table 1.

Note that in deriving the relevant equations and expressions for modeling and analysis, the general approach followed by Dincer and Rosen (2021b) is followed and then tailored to the technology under consideration.

\section{System Model and Analysis}

Assuming no thermal losses and pressure drops in the geothermal-based system components, neglecting kinetic and potential energy values, and considering the design parameters given in Table 1, a thermodynamic model of the system is developed. Also, the system is able to exchange mass, heat, and work with the environment through the system boundary. The reference environment temperature and pressure, respectively, are denoted $T_{0}$ and $P_{0}$.

General mass, energy, entropy, and exergy rate balances, respectively, for an open system in a control volume can be expressed under steady-state conditions as

$\sum_{\text {in }} \dot{m}-\sum_{\text {out }} \dot{m}=0$

$\dot{Q}-\dot{W}+\sum_{\text {in }} \dot{m} h-\sum_{\text {out }} \dot{m} h=0$ 


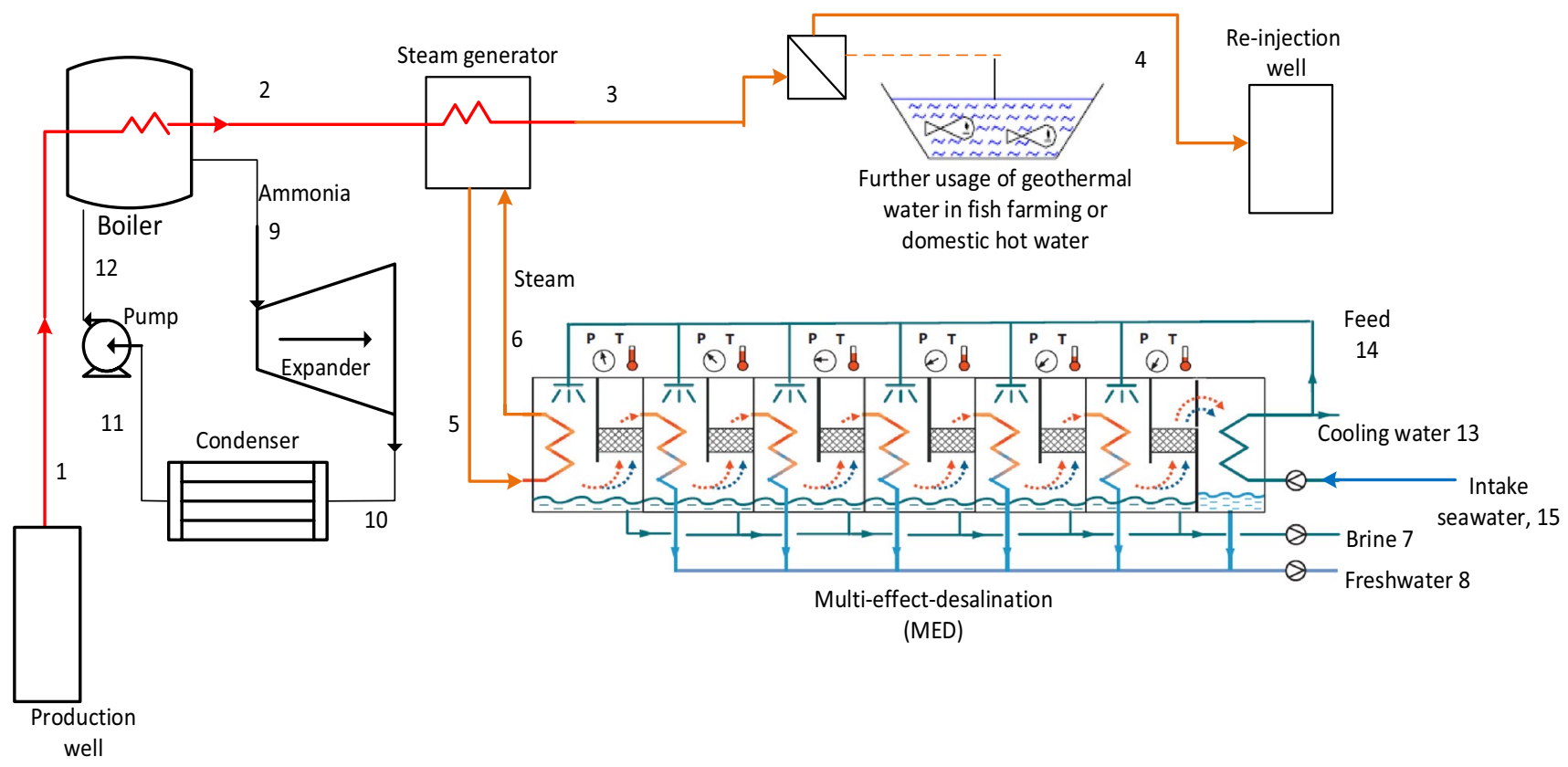

Fig. 1 Geothermal energy source used to drive ORC and MED systems

Table 1 Design parameters for the geothermal-based electricity-water production combined system

\begin{tabular}{ll}
\hline Parameter & Value \\
\hline Geothermal water temperature & $180{ }^{\circ} \mathrm{C}$ \\
Environment pressure & $101.135 \mathrm{kPa}$ \\
Environment temperature & $25^{\circ} \mathrm{C}$ \\
ORC subsystem & \\
Expander isentropic efficiency & 0.8 \\
Boiler pressure & $3.9 \mathrm{MPa}$ \\
Boiler temperature & $150{ }^{\circ} \mathrm{C}$ \\
Condenser pressure & $1.5 \mathrm{MPa}$ \\
Pump isentropic efficiency & 0.8 \\
MED subsystem & \\
Top brine temperature (TBT) & $63{ }^{\circ} \mathrm{C}$ \\
Seawater input temperature & $20{ }^{\circ} \mathrm{C}$ \\
Distillate salinity & $0 \mathrm{~g} / \mathrm{kg}$ \\
Input seawater salinity & $42 \mathrm{~g} / \mathrm{kg}$ \\
Brine salinity & $70 \mathrm{~g} / \mathrm{kg}$ \\
Number of effects & 6 \\
\hline
\end{tabular}

$\frac{\dot{Q}}{T}+\sum_{\text {in }} \dot{m} s-\sum_{\text {out }} \dot{m} s+\dot{S}_{\mathrm{gen}}=0$

$\dot{E} \dot{x}^{\dot{Q}}-\dot{E} x^{\dot{W}}+\sum_{\text {in }} \dot{m} e x-\sum_{\text {out }} \dot{m} e x-\dot{E} x_{D}=0$, where $\dot{m}, h, s$, and $e x$, respectively, denote mass flow rate, specific enthalpy, specific entropy, and specific exergy; $\dot{Q}$, $\dot{W}, \dot{S}_{g e n}$, and $\dot{E x_{D}}$, respectively, denote heat transfer rate, work rate, entropy generation rate, and exergy destruction rate; and $\dot{E x} \dot{Q}$ and $\dot{E x} \dot{W}$, respectively, denote exergy rates associated with heat and work. The latter two terms can be expressed as follows:

$\dot{E} x^{\dot{Q}}=\left(1-\frac{T_{0}}{T}\right) \dot{Q}$

$\dot{E} x^{\dot{W}}=\dot{W}$,

where $T$ is the temperature (in $\mathrm{K}$ ) at which the heat transfer process occurs and $T_{0}$ is the reference environment temperature.

The parameter $e x$ is the total specific exergy of a material flow. The total exergy of a general material flow can be expressed as the summation of its physical (or thermomechanical) exergy and chemical exergy as follows:

$e x=e x_{\mathrm{ph}}+e x_{\text {chem }}$

The specific physical flow exergy $\left(e x_{\mathrm{ph}}\right)$ indicates the maximum useful work that can be transferred to an external user as the flow reaches thermal and mechanical equilibrium with the reference environment (i.e., the restricted dead state). The specific physical exergy of a material flow can be written as 
$e x_{\mathrm{ph}}=h-h^{*}-T_{0}\left(s-s^{*}\right)$,

where properties with a superscript $*$ are quantified at the environment temperature $\left(T_{0}\right)$ and pressure $\left(P_{0}\right)$, but at the same concentration or composition as the initial state.

The specific chemical flow exergy ( $\left.e x_{\text {chem }}\right)$ is the maximum work obtainable during the transition of a flow from the restricted dead state to the total (or global) dead state. This state is achieved when the temperature, pressure, and constituent concentrations take on the values of these parameters in the reference environment. At the total deadstate condition, the concentration of each constituent in the system takes on its concentration in the environment at $T_{0}$ and $P_{0}$. Thus, the specific chemical exergy of a mixture can be expressed as

$e x_{\text {chem }}=\sum_{i=1}^{n}\left(\mu_{i}^{*}-\mu_{0, i}\right) x_{i}$

where $\mu_{i}^{*}$ is the specific chemical potential of constituent $i$ at the temperature and pressure of the reference environment, and $\mu_{0, i}$ is the specific chemical potential of constituent $i$ at the temperature, pressure, and constituent concentrations of the reference environment. Note that for a pure substance, such as pure water and pure ammonia, the chemical exergy term is zero, while for a multi-constituent substance, like seawater, the chemical exergy is not zero and must be accounted for in the analysis.

In contrast to the energy efficiency, which measures the ratio of useful energy product to the input energy, the exergy efficiency reveals the extent to which a process is reversible In general, the exergy efficiency can be defined as the exergy rate of useful process outputs to the exergy rate of process inputs. The exergy (or available energy) of useful process outputs is equal to the input exergy less the exergy destruction and the exergy loss. The destroyed exergy (or available energy consumption) represents the amount of available work that is lost due to system irreversibilities, while the exergy loss represents the amount of available work that is lost with outgoing waste streams. Therefore, the general energy and exergy efficiencies for an energy system can be written, respectively, as

$\eta=\frac{\text { Useful product energy rate }}{\text { Input energy rate }}$

$\Psi=\frac{\text { Useful product exergy rate }}{\text { Input exergy rate }}$

In the following subsections, mass, energy, entropy, and exergy rate balances are developed for the system components, broken down by system section.

\subsection{Organic Rankine Cycle (ORC)}

From Fig. 1, mass, energy, entropy, and exergy rate balances for the ammonia-based ORC components can be expressed, respectively, as follows:

Boiler

$\dot{m}_{12}=\dot{m}_{9}$

$\dot{Q}_{\text {Boiler }}=\dot{m}_{\mathrm{Geo}}\left(h_{1}-h_{2}\right)=\dot{m}_{9} h_{9}-\dot{m}_{12} h_{12}$

$\dot{m}_{12} s_{12}+\frac{\dot{Q}_{\text {Boiler }}}{T_{\text {Boiler }}}+\dot{S}_{\text {gen,Boiler }}=\dot{m}_{9} s_{9}$

$\dot{m}_{12} e x_{12}+\dot{Q}_{\text {Boiler }}\left(1-\frac{T_{0}}{T_{\text {Boiler }}}\right)=\dot{m}_{9} e x_{9}+\dot{E x}_{D, \text { Boiler }}$

Expander (exp)

$\dot{m}_{9}=\dot{m}_{10}$

$\dot{m}_{9} h_{9}=\dot{m}_{10} h_{10}+\dot{W}_{\text {exp }}$

$\dot{m}_{9} s_{9}+\dot{S}_{\text {gen,exp }}=\dot{m}_{10} s_{10}$

$\dot{m}_{9} e x_{9}=\dot{m}_{10} e x_{10}+\dot{W}_{\exp }+\dot{E} x_{D \text {,exp }}$

Condenser (cond)

$\dot{m}_{10}=\dot{m}_{11}$

$\dot{m}_{10} h_{10}=\dot{m}_{11} h_{11}+\dot{Q}_{\text {cond, ORC }}$

$\dot{m}_{10} s_{10}+\dot{S}_{\text {gen,cond }}=\dot{m}_{11} s_{11}+\frac{\dot{Q}_{\text {cond }}}{T_{\text {cond }}}$

$\dot{m}_{12} e x_{12}=\dot{m}_{11} e x_{11}+\dot{Q}_{\text {cond }}\left(1-\frac{T_{0}}{T_{\text {cond }}}\right)+\dot{E} x_{D, \text { cond }}$

Pump

$\dot{m}_{11}=\dot{m}_{12}$

$\dot{m}_{11} h_{11}+\dot{W}_{\text {pump }}=\dot{m}_{12} h_{12}$

$\dot{m}_{11} s_{11}+\dot{S}_{\text {gen,pump }}=\dot{m}_{12} s_{12}$

$\dot{m}_{11} e x_{11}=\dot{m}_{12} e x_{12}+\dot{E} x_{D, \text { pump }}$ 
The energy and exergy efficiencies of the ORC subsystem can be expressed, respectively, as

$$
\begin{aligned}
\eta_{\mathrm{ORC}} & =\frac{\dot{W}_{\text {net }}}{\dot{Q}_{\text {Boiler }}}=\frac{\dot{W}_{\text {exp }}-\dot{W}_{\text {pump }}}{\dot{Q}_{\text {Boiler }}} \\
\Psi_{\text {ORC }} & =\frac{\dot{W}_{\text {net }}}{\dot{Q}_{\text {Boiler }}\left(1-\frac{T_{0}}{T_{\text {Boiler }}}\right)} \\
& =1-\frac{\dot{E x} x_{D, \text { Boiler }}+E x_{D, \text { exp }}+E x_{D, \text { cond }}+E x_{D, \text { pump }}}{\dot{Q}_{\text {Boiler }}\left(1-\frac{T_{0}}{T_{\text {Boiler }}}\right)}
\end{aligned}
$$

\subsection{Multi-effect Distillation (MED) Desalination System}

A process flow diagram of a parallel-feed MED desalination system is shown in Fig. 2. In the study, the work rate required for pumping feed, brine, and distillate streams are not considered. Denoting salt concentration $w$ and using subscripts $f, B$, and $D$, respectively, to denote feed, brine and distillate, mass, energy, entropy, and exergy rate balances for the MED effects, the condenser, and the overall unit can be written, as follows:

First Effect

$$
\begin{aligned}
& w_{s w} \dot{m}_{f 1}=w_{B, 1}\left(\dot{m}_{f 1}-\dot{m}_{D 1}\right) \\
& \dot{Q}_{\text {source }}=\dot{m}_{f 1} c_{p}\left(T_{1}-T_{f}\right)+\dot{m}_{D 1} h_{f g 1} \\
& \dot{m}_{14} s_{14}+\frac{\dot{Q}_{\text {source }}}{T_{S}}+\dot{S}_{\text {gen }}=\dot{m}_{B 1} s_{B 1}+\dot{m}_{D 1} s_{D 1}
\end{aligned}
$$

$\dot{m}_{14} e x_{14}+\dot{Q}_{\text {source }}\left(1-\frac{T_{0}}{T_{s}}\right)=\dot{m}_{B 1} e x_{B 1}+\dot{m}_{D 1} e x_{D 1}+\dot{E x} x_{D, \text { effect } 1}$

Effect $i$ to $n$

$w_{s w} \dot{m}_{f 1}+w_{B(i-1)} \dot{m}_{B r(i-1)}=w_{B(i)} \dot{m}_{B(i)}$

$\dot{Q}_{i-1}=\dot{m}_{D, n-1} h_{f g n-1}=\dot{m}_{D, i} h_{f g i}+\dot{m}_{B, i-1} c_{p, w}\left(T_{i-1}-T_{i}\right)$

$\dot{m}_{i} s_{i}+\frac{\dot{Q}_{i-1}}{T_{i-1}}+\dot{S}_{g e n}=\dot{m}_{B i} s_{B, i}+\dot{m}_{D, i} s_{D, i}$

$\dot{m}_{i} e x_{i}+\dot{Q}_{i-1}\left(1-\frac{T_{0}}{T_{i-1}}\right)=\dot{m}_{B i} e x_{B i}+\dot{m}_{D i} e x_{D i}+\dot{E} x_{D, \text { effect } i}$

$T_{i}=T_{v s, i}+B P E_{i} \quad i=1,2, \ldots, n$

Here, $T_{i}$ is the temperature of vapor generated in effect $i$, which is a function of the pure vapor saturation temperature $\left(T_{v s, i}\right)$ and the boiling point elevation (BPE) (Farsi et al. 2016).

An energy rate balance for the condenser, in which vapor from the last effect is condensed using cooling water $(c w)$, can be written as follows:

$\dot{Q}_{\text {cond }}=\dot{m}_{D, n} h_{f g, n}=\left(\dot{m}_{f}+\dot{m}_{c w}\right) c_{p}\left(T_{\text {sea }}-T_{f}\right)$

Steam Generator (SG) Heat Exchanger

$\dot{m}_{s, \text { in }}=\dot{m}_{s, \text { out }}$

$\dot{m}_{2}=\dot{m}_{3}$

$\dot{m}_{2} h_{2}+\dot{m}_{s, \text { out }} h_{s, \text { out }}=\dot{m}_{3} h_{3}+\dot{m}_{s, \text { in }} h_{s, \text { in }}$

$\dot{m}_{2} s_{2}+\dot{m}_{s, \text { out }} s_{s, \text { out }}+\dot{S}_{\text {gen }, S G}=\dot{m}_{3} s_{3}+\dot{m}_{s, \text { in }} s_{s, \text { in }}$

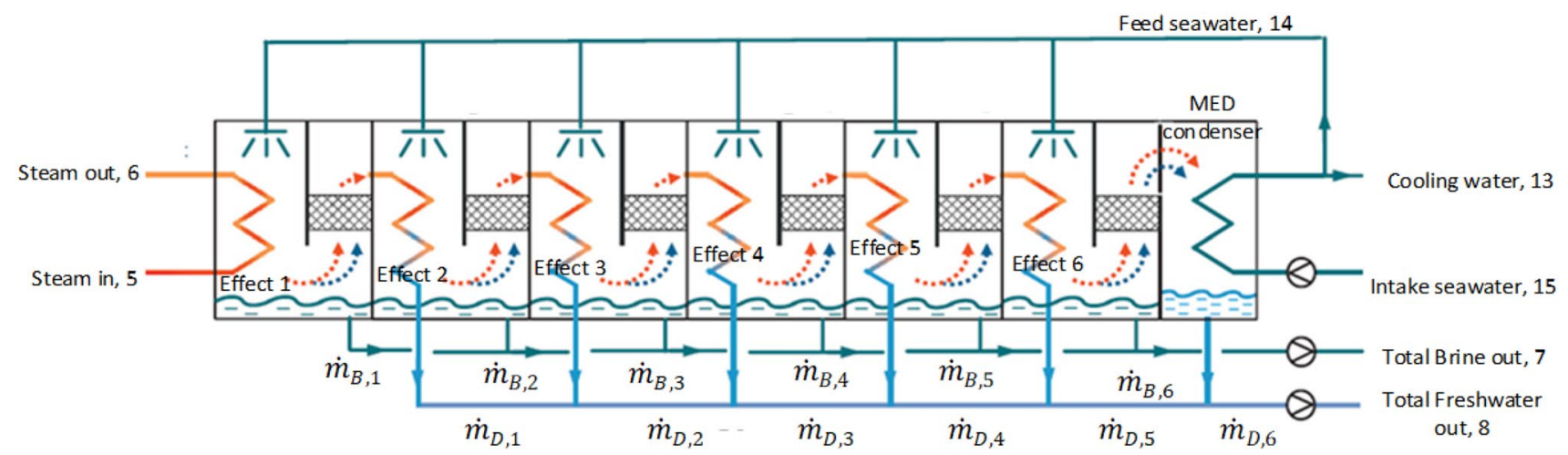

Fig. 2 Parallel-feed MED unit 
$\dot{m}_{2} e x_{2}+\dot{m}_{s, \text { out }} e x_{s, \text { out }}+\dot{S}_{\text {gen }, S G}=\dot{m}_{3} e x_{3}+\dot{m}_{s, \text { in }} e x_{s, \text { in }}+\dot{E x} x_{D, S G}$

Effects Block

$\dot{m}_{6}=\dot{m}_{7}+\dot{m}_{8}+\dot{m}_{13}$

$\dot{m}_{6} h_{6}+\dot{Q}_{S G}=\dot{m}_{7} h_{7}+\dot{m}_{8} h_{8}+\dot{m}_{13} h_{13}$

$\dot{m}_{6} s_{6}+\frac{\dot{Q}_{S G}}{T_{S}}+\dot{S}_{\text {gen,MED }}=\dot{m}_{7} s_{7}+\dot{m}_{8} s_{8}+\dot{m}_{13} s_{13}$

$\dot{m}_{6} e x_{6}+\dot{Q}_{S G}\left(1-\frac{T_{0}}{T_{s}}\right)=\dot{m}_{7} e x_{7}+\dot{m}_{8} e x_{8}+\dot{m}_{13} e x_{13}+\dot{E x_{D, \mathrm{MED}}}$ of a desalination system is a function of the reference environment temperature, the feed seawater concentration, the recovery ratio (i.e., $\dot{m}_{D} / \dot{m}_{f}$ ), and the product salinity. One type of exergy efficiency is the ratio of minimum exergy rate required for desalination to the actual exergy rate input to the system. Then, the MED desalination exergy efficiency can be expressed as

$\Psi_{\mathrm{MED}}=\frac{\dot{W}_{\mathrm{min}, \mathrm{MED}}}{\dot{E} x_{\mathrm{in}, \mathrm{MED}}}=\frac{\dot{m}_{7} e x_{7}+\dot{m}_{8} e x_{8}-\dot{m}_{15} e x_{15}}{\dot{m}_{s, \text { in }} e x_{s, \text { in }}-\dot{m}_{s, \text { out }} e x_{s, \text { out }}}$

Also, the exergy efficiency of an MED system can be expressed, noting that the useful exergy rate is the exergy input rates minus the exergy loss and exergy destruction rates. Thus, the exergy efficiency can be expressed based on the ratio of the summation of the exergy loss and exergy destruction rates to the total input exergy rate as follows:

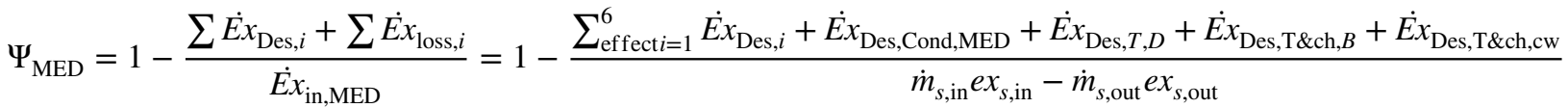

We now determine the minimum work required for separation of feed into brine and distillate to evaluate the exergy efficiency of the desalting process. The minimum required work for separation can be defined for reversible desalination operation, in which the entropy generation rate is zero and all input and output streams (except distillate) are brought to the total dead state. The distillate, as the sole useful product, is brought to the restricted dead state (i.e., reference environment temperature and pressure). Here, the process streams interacting with the desalination system are feed, brine, and distillate. The minimum work rate required for desalting can be written in terms of the exergy rates corresponding to the process streams as follows:

$\dot{W}_{\text {min,MED }}=\dot{m}_{D} e x_{D}+\dot{m}_{B} e x_{B}-\dot{m}_{s w} e x_{s w}$

Here, the control volume is selected, such that all streams are in thermal and mechanical equilibrium with the reference environment.

The common energetic performance ratio (PR) of a thermal MED system can be defined as the ratio of mass flow rate of the distillate product to the mass flow rate of steam as the heating medium in the first effect. That is

$P R=\frac{\dot{m}_{D, \text { total }}}{\dot{m}_{s}}$

The exergy efficiency of a desalination system is a measure of its actual effectiveness compared to its performance under reversible conditions, recognizing that exergy destruction and loss reduce exergy efficiency. The exergy efficiency
Here, the exergy destruction rate indicates the lost available work rate due to irreversibilities (i.e., $\left.\sum \dot{E} x_{\text {Des }}=\sum T_{0} \dot{S}_{\text {gen }}\right)$ and the exergy loss rate indicates the lost available work rate due to releasing waste streams (i.e., brine and cooling water) to the environment, while $\dot{E} x_{\text {Des, } T, D}$ is the exergy destruction rate associated with bringing the distillate temperature to the reference environment temperature. Then, the exergy destruction rate due to the temperature disequilibrium for the distillate can be written as

$\dot{E} x_{\text {Des }, T, D}=\dot{m}_{8} e x_{8}\left(T_{8}, P_{0}, w_{8}\right)-\dot{m}_{8} e x_{8}\left(T_{0}, P_{0}, w_{8}\right)$

Here, $w_{8}$ is assumed to be zero. For the brine and cooling water streams, the exergy destruction rates are associated with bringing both temperature and concentration to the reference environment temperature and constituent concentration values (i.e., $\dot{E} x_{\text {Des,T\&ch, } B}$ and $\dot{E} x_{\text {Des,T\&ch,cw }}$ ). Then, the exergy destruction rates associated with temperature disequilibrium and chemical disequilibrium for the brine and cooling water can be written, respectively, as

$\dot{E} x_{\text {Des,T\&ch, } B}=\dot{m}_{7} e x_{7}\left(T_{7}, P_{0}, w_{7}\right)-\dot{m}_{7} e x_{7}\left(T_{0}, P_{0}, w_{0}\right)$

$\dot{E} x_{\text {Des,T\&ch,cw }}=\dot{m}_{13} e x_{13}\left(T_{13}, P_{0}, w_{13}\right)-\dot{m}_{13} e x_{13}\left(T_{0}, P_{0}, w_{0}\right)$

The last terms on the right side of these two equations are zero, because they are at the total dead-state conditions. 


\subsection{Sustainability Analysis}

Sustainable development involves among other factors the use of sustainable energy resources, often in an efficient manner. Therefore, both employing sustainable energy resources in energy systems and using these resources efficiently are important in sustainable development. This means that, even the sustainable energy resources become widely available and inexpensive, increased efficiency is still preferred for reducing environmental impacts (Rosen et al. 2008). Exergy methods play a key role in improving efficiency of energy systems using sustainable energy resources. The use of such methods helps in maximizing the benefits that can be derived from these systems while minimizing the environmental impacts associated with them.

By utilizing sustainable or renewable sources of energy, as well as using efficiently non-renewable sources such as natural gas, reduced environmental impact and greater sustainability can be attained. The sustainable index $(S I)$ is employed here to relate exergy and environmental impact concepts as follows:

$\mathrm{SI}=\frac{1}{D_{P}}$

Here, $D_{P}$ is the depletion number, defined as the ratio of destroyed exergy to exergy input. This equation shows how decreasing the environmental impact of a system can be attained by decreasing the exergy destruction. The sustainability index thus indicates a measure of the extent of the contribution of exergy efficiency to sustainable development. The sustainability index can be written as follows:

$\mathrm{SI}=\frac{1}{1-\Psi}$

where $\Psi$ denotes exergy efficiency. It can be seen that improving the exergy efficiency of a system leads to increase in its sustainability index and consequently a reduction in the environmental impacts associated with it.

The exergy efficiencies of ORC and MED systems are presented in Eqs. 29 and 52, respectively. With these, the overall exergy efficiency of the geothermal-based electricityfreshwater combined system can be written as

\section{Results and Discussion}

A thermodynamic model using mass, energy, entropy, and exergy rate balances as well as other relations is developed for each component of the geothermal-based combined system. Then, the thermodynamic model is simulated in Engineering Equation Software (EES) using the thermodynamic properties of the working fluids (i.e., seawater, distillate, brine, and ammonia) at the state points. By solving simultaneously the thermodynamic equations in the EES, the thermodynamic properties (temperature, pressure, specific enthalpy, specific entropy, and specific exergy) for all state points are evaluated. Table 2 presents the thermodynamic properties for all state points of the geothermal combined electricity-freshwater system. In addition, Table 3 provides, for each effect, the effect pressure and temperature, specific entropy, specific enthalpy and specific exergy of brine, and entropy generation and exergy destruction rates.

It is seen from Table 3 that, among the effects of the MED unit, the exergy destruction rate is greater for the first effect than the other effects (the first effect being responsible for $60 \%$ of the total MED exergy destruction rate), because only the first effect exchanges heat with the high-temperature heat source. In other words, the temperature difference between the heat exchanging mediums (i.e., steam and feed seawater) in the first effect is more than in other effects. Therefore, the exergy destruction rate in the first effect exceeds that of other effects. An important way to reduce or minimize the irreversibility in the first MED effect is reducing the temperature difference. In fact, the temperature profiles of the heat exchange mediums should be matched, so the thermal energy exchanges are maximal.

Once the thermodynamic properties of state points are determined in the geothermal-based system, the performance ratio, energy efficiency, and exergy efficiency of the subsystems (i.e., ORC and MED) and the overall system can be calculated.

The produced freshwater rate in each MED effect and the electrical power produced by the ORC system are provided in Table 4. As mentioned before, underground geothermal water supplies heat for the boiler and steam generator. The

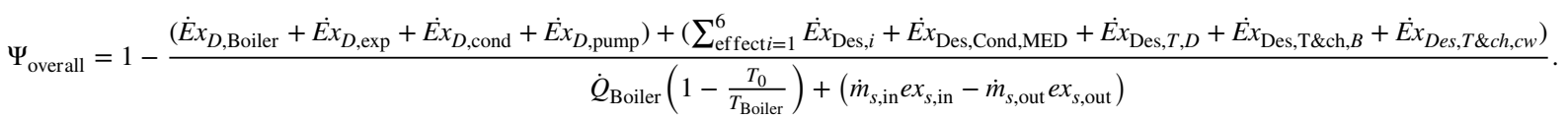

Note that the exergy rate of intake seawater input (stream 15) is zero, because it is at the total dead state; hence, the exergy rate of this input stream is not written in the denominator of Eq. 58. required mass flow rate of geothermal water from the production well and the temperature of the geothermal source are important factors in determination of system capacity. An energy source like a diesel generator can be used as a backup system in the case where there is insufficient geothermal energy. 
Table 2 Input and evaluated thermodynamic properties at state points in Fig. 1
Table 3 Input and evaluated thermodynamic parameters for MED effects

\begin{tabular}{llllllll}
\hline State no & Fluid & $T\left({ }^{\circ} \mathrm{C}\right)$ & $P(\mathrm{MPa})$ & $h(\mathrm{~kJ} / \mathrm{kg})$ & $s(\mathrm{~kJ} / \mathrm{kg} . \mathrm{K})$ & $e x(\mathrm{~kJ} / \mathrm{kg})$ & $x(\mathrm{~kg} / \mathrm{kg})$ \\
\hline 0 & Seawater & 25 & 101.135 & 98.7 & 0.34 & 0 & 0.042 \\
0 & Water & 25 & 101.135 & 104.3 & 0.36 & 0 & - \\
0 & Ammonia & 25 & 101.135 & 1546 & 6.6 & 0 & - \\
1 & Water & 180 & 1.003 & 763.1 & 2.139 & 130 & - \\
2 & Water & 115 & 0.98 & 483.2 & 1.47 & 48.74 & - \\
3 & Water & 98 & 0.98 & 411.4 & 1.28 & 28.61 & - \\
4 & Water & 86 & 0.98 & 361 & 1.146 & 19.35 & - \\
5 & Steam & 95 & 0.084 & 2668 & 1.25 & 462.4 & - \\
6 & Steam & 95 & 0.084 & 398.1 & 7.4 & 29.98 & - \\
7 & Brine & 55 & 0.016 & 209.9 & 0.68 & 6.065 & 0.07 \\
8 & Distillate & 55 & 0.016 & 230.2 & 0.77 & 9.44 & 0 \\
9 & Ammonia & 150 & 2.9 & 1738 & 5.44 & 536 & - \\
10 & Ammonia & 79.15 & 1.5 & 1611 & 5.54 & 382 & - \\
11 & Ammonia & 38.7 & 1.5 & 384.1 & 1.62 & 320.8 & - \\
12 & Ammonia & 39.53 & 3.8 & 389.3 & 1.62 & 325 & - \\
13 & Seawater & 30.44 & 0.101 & 120.2 & 0.416 & 0.1672 & 0.042 \\
14 & Seawater & 30.44 & 0.101 & 120.2 & 0.416 & 0.1672 & 0.042 \\
15 & Seawater & 25 & 0.101 & 98.7 & 0.34 & 0 & 0.042 \\
\hline
\end{tabular}

\begin{tabular}{llllllll}
\hline $\begin{array}{l}\text { Effect } \\
\text { no }\end{array}$ & $\begin{array}{l}T \\
\left({ }^{\circ} \mathrm{C}\right)\end{array}$ & $\begin{array}{l}P \\
(\mathrm{kPa})\end{array}$ & $\begin{array}{l}h_{B} \\
(\mathrm{~kJ} / \mathrm{kg})\end{array}$ & $\begin{array}{l}s_{B} \\
(\mathrm{~kJ} / \mathrm{kg} \cdot \mathrm{K})\end{array}$ & $\operatorname{ex}_{B}(\mathrm{~kJ} / \mathrm{kg})$ & $\begin{array}{l}\dot{S}_{\text {gen }} \\
(\mathrm{kW})\end{array}$ & $\begin{array}{l}\dot{E x_{D e s}} \\
(\mathrm{~kW})\end{array}$ \\
\hline 1 & 63 & 23 & 240.8 & 0.78 & 9.45 & 4.2 & 1641 \\
2 & 59.8 & 20 & 230.2 & 0.75 & 7.9 & 0.77 & 231 \\
3 & 56.6 & 17 & 219 & 0.72 & 6.5 & 0.66 & 197.8 \\
4 & 53.4 & 15 & 207.4 & 0.68 & 5.2 & 0.56 & 167.4 \\
5 & 50.2 & 13 & 195.5 & 0.65 & 4.14 & 0.47 & 140 \\
6 & 47 & 11 & 183.4 & 0.61 & 3.16 & 0.39 & 116 \\
\hline
\end{tabular}

The exergy destruction rate breakdown for all components of the combined system is shown in Fig. 3a. It is seen that the boiler has the greatest exergy destruction rate. Heat transfer over a large temperature difference occurring in the boiler is the main cause of irreversibilities. For the ORC condenser and steam generator, the phase change experienced by the vapor and condensed working fluid (ammonia in the ORC condenser and water in the steam generator) leads to the significant exergy destruction rates in these heat exchangers. Therefore, reducing the temperature difference in both the boiler and the steam generator heat exchanger may decrease their exergy destruction rates.

In Fig. 3b, the percentage breakdown of exergy destruction rate by the component is shown for the MED unit, which is an important part of the overall geothermal-based ORCMED system. As mentioned before, it is necessary to take into account the exergy destruction rate associated with the temperature and chemical disequilibrium of the brine and freshwater with the reference environment when considering the irreversibilities in the desalting process. Figure $3 \mathrm{~b}$ shows that the exergy destruction rate associated with temperature and chemical disequilibrium of the brine and temperature disequilibrium of the freshwater, respectively, are responsible for $14 \%$ and $6 \%$ of MED total exergy destruction rate.

Figure 4 shows the effect of seawater temperature and salinity on the overall exergy efficiency of the geothermal combined system. Higher overall exergy efficiencies can be obtained at higher seawater temperatures, due to the decrease of the total exergy destruction of all stages with increasing feed seawater temperature. Furthermore, with increasing seawater salt concentration, the minimum exergy required for desalting increases. This results in an increase of the exergy efficiency of the MED subsystem and also a slight increase in the overall exergy efficiency of the combined system.

Figure 5 shows the effect of geothermal water resource temperature and boiler pressure (the highest pressure in the system) on the overall exergy efficiency of the geothermal-based combined MED-ORC system. It is seen that the overall exergy efficiency of the geothermal-based 
Table 4 Heat rate, work rate, and total freshwater production rate of the geothermal-based ORC-MED system

\begin{tabular}{ll}
\hline Parameter & Value \\
\hline$\eta_{\text {ORC }}$ & $9.0 \%$ \\
$\Psi_{\text {ORC }}$ & $34.15 \%$ \\
$P R$ & 3.62 \\
$\Psi_{\text {MED }}$ & $20.58 \%$ \\
$\Psi_{\text {overall }}$ & $38.06 \%$ \\
$\dot{Q}_{\text {Boiler }}$ & $79,864 \mathrm{~kW}$ \\
$\dot{Q}_{\text {Cond,ORC }}$ & $72,669 \mathrm{~kW}$ \\
$\dot{Q}_{\text {SG }}$ & $20,481 \mathrm{~kW}$ \\
$\dot{Q}_{\text {Cond,MED }}$ & $8749 \mathrm{~kW}$ \\
$\dot{W}_{\text {Expander }}$ & $7500 \mathrm{~kW}$ \\
$\dot{W}_{\text {Pump }}$ & $305 \mathrm{~kW}$ \\
Freshwater production rate in each effect & $\dot{m}_{D 1}=7.6 \mathrm{~kg} / \mathrm{s} ; \dot{m}_{D 2}$ \\
& $=6.6 \mathrm{~kg} / \mathrm{s} ; \dot{m}_{D 3}$ \\
& $=5.7 \mathrm{~kg} / \mathrm{s} ; \dot{m}_{D 4}$ \\
& $=4.9 \mathrm{~kg} / \mathrm{s} ;$ \\
& $\dot{m}_{D 5}=4.2 \mathrm{~kg} / \mathrm{s} ; \dot{m}_{D 6}$ \\
& $=3.6 \mathrm{~kg} / \mathrm{s} ; \dot{m}_{D, t o t a l}$ \\
& $=32.7 \mathrm{~kg} / \mathrm{s}$ \\
Cooling water mass flow rate in MED & $19.04 \mathrm{~kg} / \mathrm{s}$ for each \\
Steam flow rate into MED & effect (equal feed \\
Feothermal underground water mass flow rate & mass flow rates \\
& for all effects $)$ \\
& $107.4 \mathrm{~kg} / \mathrm{s}$ \\
& $9.02 \mathrm{~kg} / \mathrm{s}$ \\
& $585.4 \mathrm{~kg} / \mathrm{s}$ \\
& $59.21 \mathrm{~kg} / \mathrm{s}$ \\
\hline & \\
& \\
&
\end{tabular}

combined MED-ORC system reaches its minimum value at a geothermal water resource temperature of $175^{\circ} \mathrm{C}$. This is obtained when the work rate from the expander and freshwater production rate from MED, respectively, are $7500 \mathrm{~kW}$ and $98 \mathrm{~kg} / \mathrm{s}$. It is shown that, at fixed work and freshwater production rates, as the system boiler pressure increases, the exergy destruction rates of the system decrease due to the decrease in the ammonia mass flow rate. This results in an increase in the exergy efficiency of the overall system.

The effect of reference environment temperature on the exergy destruction rate and sustainability index of the MED and ORC systems are shown in Fig. 6. As the reference environment temperature increases from 20 to $35^{\circ} \mathrm{C}$, the exergy destruction rates for both the MED and ORC systems decrease and the corresponding sustainability indexes increase. It is seen that, as the reference environment temperature rises from 20 to $35^{\circ} \mathrm{C}$, the exergy destruction rate decreases for the MED and ORC systems, respectively, from 6474 to $4217 \mathrm{~kW}$ and from $16,270 \mathrm{~kW}$ to $13,459 \mathrm{~kW}$. The corresponding sustainability index for (a)

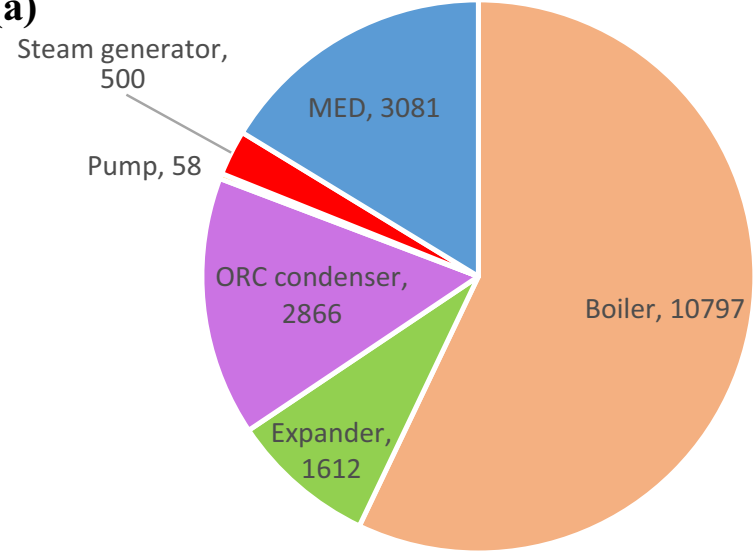

Total exergy destruction rate in the overall system $=18914 \mathrm{~kW}$

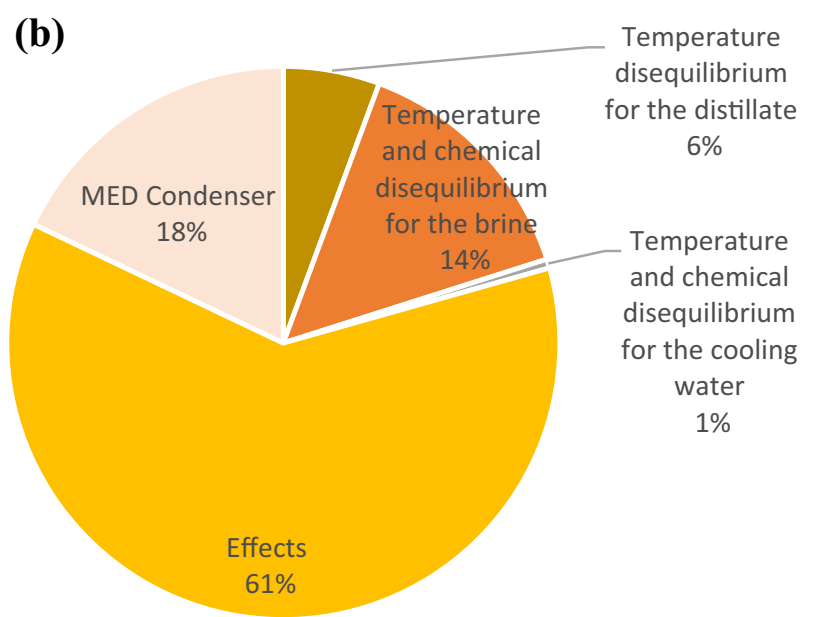

Total exergy destruction rate in MED=3081 kW

Fig. 3 a Breakdown by component of exergy destruction rates $(\mathrm{kW})$ for geothermal-based ORC-MED system; $\mathbf{b}$ percentage breakdown of exergy destruction rate by component for the MED unit in the geothermal-based ORC-MED system

the MED and ORC systems increases respectively from 1.16 to 1.2 and 1.5 to 1.6 . The same trend can be seen in Fig. 7, where the sustainability indexes are observed to rise with increasing temperature of the geothermal water source. However, the exergy destruction rates for both the MED and ORC systems decrease. It can be concluded that the exergy analysis of geothermal-based combined system assists in evaluating the efficiency, environmental impact, and sustainability of the system.

\section{Conclusions}

Energy and exergy assessments, as well as sustainability analyses, are carried out for a geothermal-based combined system for electricity and freshwater production. 


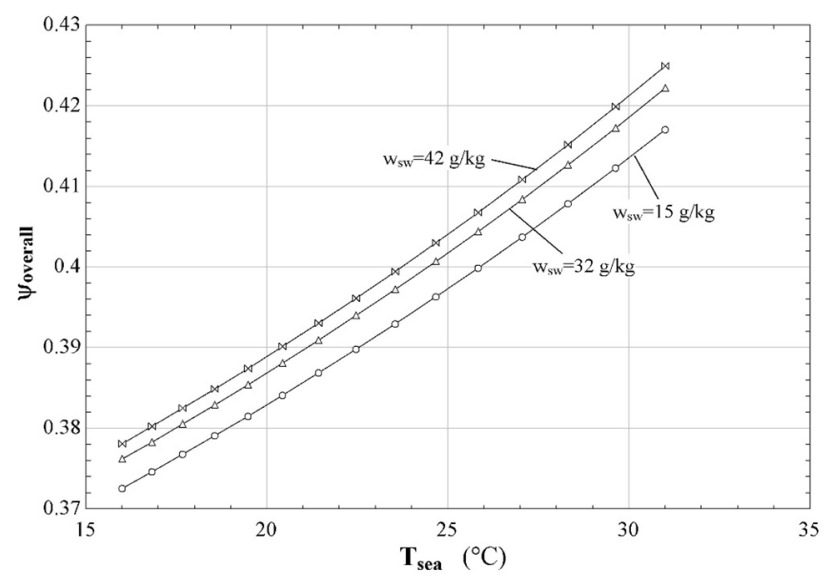

Fig. 4 Variation of overall exergy efficiency of the geothermal-based combined MED-ORC system with the seawater temperature at several seawater salt concentrations

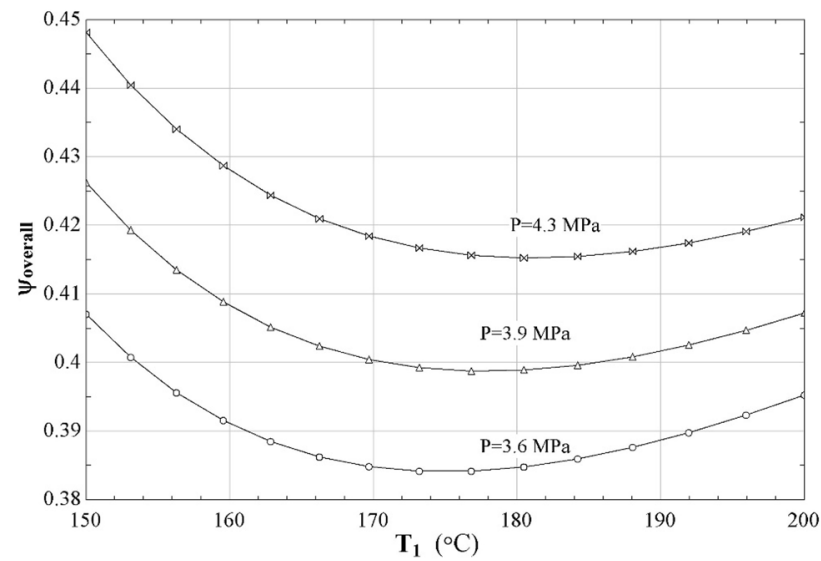

Fig. 5 Variation of overall exergy efficiency of the geothermal-based combined MED-ORC system with the geothermal water resource temperature at several boiler pressures

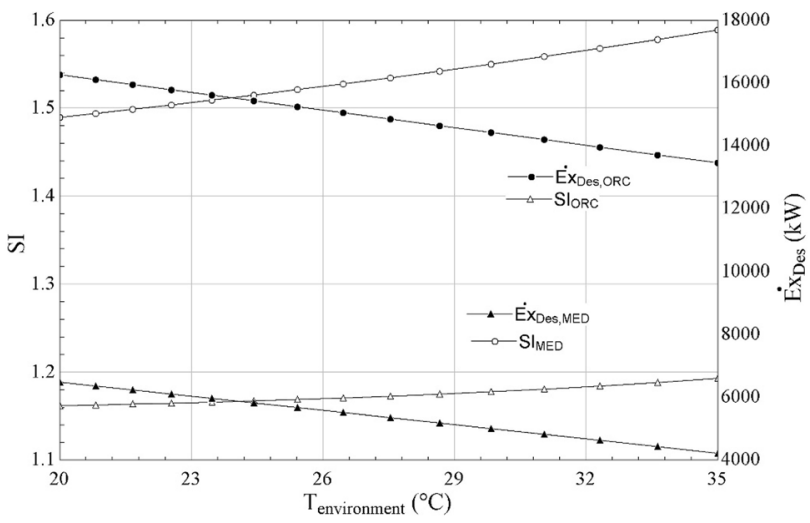

Fig. 6 Effect of reference environment temperature on exergy destruction rate and sustainability index for the ORC and MED systems

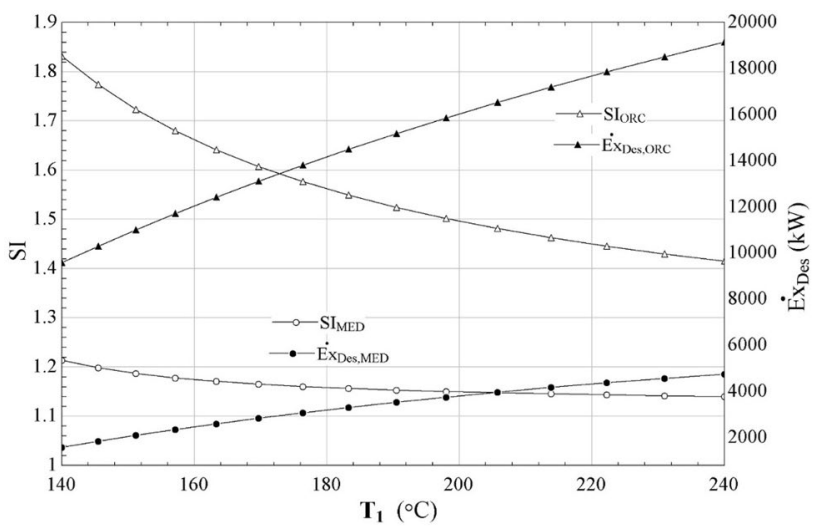

Fig. 7 Effect of geothermal water source temperature $\left(\mathrm{T}_{1}\right)$ on exergy destruction rate and sustainability index for the ORC and MED systems

By integrating an organic Rankine cycle with multi-effect distillation desalination, the overall exergy efficiency of the combined system ( $\Psi_{\text {overall }}=38 \%$ ) is found to be higher than that of subsystems operating separately (i.e., $\Psi_{\mathrm{MED}}=20.5 \%$ and $\left.\Psi_{\mathrm{ORC}}=34 \%\right)$. Therefore, integration of ORC and MED systems driven by geothermal energy can potentially increase exergy efficiency, and reduce both exergy destruction and environmental impact. The greatest exergy destruction rates are associated with the boiler, mainly due to heat transfer over large temperature differences. Among MED effects, the first effect has the highest exergy destruction rate (being responsible for $60 \%$ of total exergy destruction rate in MED), because only the first effect exchanges thermal energy with the high-temperature steam. Therefore, to reduce the exergy destruction rate in the first effect of MED, the temperature profiles of mediums in the heat exchanger should be matched to maximize the thermal energy exchanges. The exergy destruction rates associated with temperature disequilibrium of the freshwater and temperature and chemical disequilibrium of the brine, respectively, are responsible for $6 \%$ and $14 \%$ of total exergy destruction rate of the MED unit. Finally, it is determined via the sustainability analysis that, as the reference environment temperature and geothermal water source temperature increase, the sustainability indexes for both ORC and MED subsystems increase, while the corresponding exergy destruction rates decrease. It can be concluded that exergy analysis plays an important role in assessing the use of sustainable energy resources in seawater desalination technologies. Although other important factors like economics, safety, and environmental impacts are incorporated in design and modification of renewable energy-based desalination systems, exergy methods provide practical information on prospective system design and performance improvements to engineers and scientists. 
Furthermore, higher overall exergy efficiencies of the system can be obtained at higher seawater temperatures and salinities. The exergy destruction rates associated with temperature disequilibrium of the freshwater and temperature and chemical disequilibrium of the brine, respectively, are found to be $6 \%$ and $14 \%$ of the total exergy destruction rate of the MED desalination system.

Acknowledgements The authors are grateful for support provided by the Natural Sciences and Engineering Research Council of Canada.

Funding This study was funded by the Natural Sciences and Engineering Research Council of Canada.

\section{Declarations}

Conflict of interest The authors have no conflicts of interest to declare that are relevant to the content of this article.

Open Access This article is licensed under a Creative Commons Attribution 4.0 International License, which permits use, sharing, adaptation, distribution and reproduction in any medium or format, as long as you give appropriate credit to the original author(s) and the source, provide a link to the Creative Commons licence, and indicate if changes were made. The images or other third party material in this article are included in the article's Creative Commons licence, unless indicated otherwise in a credit line to the material. If material is not included in the article's Creative Commons licence and your intended use is not permitted by statutory regulation or exceeds the permitted use, you will need to obtain permission directly from the copyright holder. To view a copy of this licence, visit http://creativecommons.org/licenses/by/4.0/.

\section{References}

Abdolalipouradl M, Mohammadkhani F, Khalilarya S, Yari M (2020) Thermodynamic and exergoeconomic analysis of two novel trigeneration cycles for power, hydrogen and freshwater production from geothermal energy. Energy Conv Manag 226:113544

Aboelmaaref MM, Zayed ME, Zhao J, Li W, Askalany AA, Ahmed MS, Ali ES (2020) Hybrid solar desalination systems driven by parabolic trough and parabolic dish CSP technologies: technology categorization, thermodynamic performance and economical assessment. Energy Conv Manag 220:113103

Ahmadi E, McLellan B, Mohammadi-Ivatloo B, Tezuka T (2020) The role of renewable energy resources in sustainability of water desalination as a potential fresh-water source: an updated review. Sustainability 12(13):5233

Alavy M, Peiris M, Wang J, Rosen MA, (2021) Assessment of a novel phase change material-based thermal caisson for geothermal heating and cooling. Energy Conv Manag 234:113928

Anand B, Shankar R, Murugavelh S, Rivera W, Prasad KM, Nagarajan R (2021) A review on solar photovoltaic thermal integrated desalination technologies. Renew Sustain Energy Rev 141:110787

Birney CI, Jones MC, Webber ME (2019) A Spatially resolved thermodynamic assessment of geothermal powered multi-effect brackish water distillation in Texas. Resources 8(2):65

Bundschuh J, Ghaffour N, Mahmoudi H, Goosen M, Mushtaq S, Hoinkis J (2015) Low-cost low-enthalpy geothermal heat for freshwater production: innovative applications using thermal desalination processes. Renew Sustain Energy Rev 43:196-206

Campione A, Cipollina A, Calise F, Tamburini A, Galluzzo M, Micale G (2020) Coupling electrodialysis desalination with photovoltaic and wind energy systems for energy storage: dynamic simulations and control strategy. Energy Conv Manag 216:112940

Cuce E, Cuce PM, Saxena A, Guclu T, Besir AB (2020) Performance analysis of a novel solar desalination system-Part 1: the unit with sensible energy storage and booster reflector without thermal insulation and cooling system. Sustain Energy Technol Assessments 37:100566

Dincer I, Rosen MA (2021a) Thermal energy storage: systems and applications, 3d edn. Wiley, London

Dincer I, Rosen MA (2021b) Exergy: energy, environment and sustainable development, 3d edn. Elsevier, Oxford

Farsi A, Dincer I (2019) Development and evaluation of an integrated MED/membrane desalination system. Desalination 463:55-68

Farsi A, Mohammadi SH, Ameri M (2016) An efficient combination of transcritical $\mathrm{CO}_{2}$ refrigeration and multi-effect desalination: energy and economic analysis. Energy Convers Manage 127:561-575

Fytikas M, Andritsos N, Dalabakis P, Kolios N (2005) Greek geothermal update 2000-2004. In: Proceedings of the 2005 World Geothermal Congress, pp 1-8

Ghazaie SH, Sadeghi K, Sokolova E, Fedorovich E, Shirani A (2020) Comparative analysis of hybrid desalination technologies powered by SMR. Energies 13(19):5006

Gnaifaid H, Ozcan H (2021) Development and multiobjective optimization of an integrated flash-binary geothermal power plant with reverse osmosis desalination and absorption refrigeration for multigeneration. Geothermics 89: 101949.

Karytsas K, Alexandrou V, Boukis I (2002) The Kimolos geothermal desalination project. Workshop on Possibilities of Geothermal Energy Development in the Aegean Islands Region, Greece

Kasaeian A, Sharifi S, Yan WM (2018) Novel achievements in the development of solar ponds: a review. Sol Energy 174:189-206

Khan SUD, Khan SUD, Haider S, El-Leathy A, Rana UA, Danish SN, Ullah R (2017) Development and techno-economic analysis of small modular nuclear reactor and desalination system across Middle East and North Africa region. Desalination 406:51-59

Kilkis S, Krajacic G, Duic N, Rosen MA, Al-Nimr MA (2020) Advances in integration of energy, water and environment systems toward climate neutrality for sustainable development. Energy Conv Manag 225:113410

Koohi-Fayegh S, Rosen MA ( 2020) A review of energy storage types, applications and recent developments. J Energy Storage 27:101047

Marques JG, Costa AL, Pereira C (2020) Thermodynamic study of a novel trigeneration process of hydrogen, electricity and desalinated water: The case of $\mathrm{Na}-\mathrm{OH}$ thermochemical cycle, SCWR nuclear power plant and MED desalination installation. Energy Conv Manag 209:112648

Missimer TM, Ng KC, Thu K, Kim Y (2014) Systems and methods for integrated geothermal electricity generation and water desalination. United States Provisional Patent Application, 6197081

Mosaffa AH, Farshi LG (2021) Thermodynamic feasibility evaluation of an innovative salinity gradient solar ponds-based ORC using a zeotropic mixture as working fluid and LNG cold energy. Appl Thermal Eng 186:116488

Musharavati F, Khanmohammadi S, Pakseresht A (2021) Proposed a new geothermal based poly-generation energy system including Kalina cycle, reverse osmosis desalination, electrolyzer amplified with thermoelectric: 3E analysis and optimization. Appl Thermal Eng 187:116596

Nassrullah H, Anis SF, Hashaikeh R, Hilal N (2020) Energy for desalination: a state-of-the-art review. Desalination 491:114569

Panagopoulos A (2021) Water-energy nexus: desalination technologies and renewable energy sources. Environ Sci Pollut Res 28:1-14

Petrovic A, Delibasic B, Filipovic J, Petrovic A, Lomovic M (2018) Thermoeconomic and environmental optimization of geothermal water desalination plant with ejector refrigeration system. Energy Convers Manage 178:65-77 
Rezaie B, Rosen MA (2020) The energy-water-food nexus: a framework for sustainable development modeling. Energy Equipment and Systems 8(2):179-201

Rosen MA, Koohi-Fayegh S (2017) Geothermal energy: sustainable heating and cooling using the ground. John Wiley \& Sons, UK

Rosen MA, Dincer I, Kanoglu M (2008) Role of exergy in increasing efficiency and sustainability and reducing environmental impact. Energy Policy 36(1):128-137

Rosen MA, Koohi-Fayegh S (2016) Cogeneration and district energy systems: modelling, analysis and oOptimization. Institution of Engineering and Technology, London
Tong X, Liu S, Chen Y, Crittenden J (2020) Thermodynamic analysis of a solar thermal facilitated membrane seawater desalination process. J Clean Prod 256:120398

Vaithilingam S, Gopal ST, Srinivasan SK, Manokar AM, Sathyamurthy R, Esakkimuthu GS, Kumar R, Sharifpur M (2020) An extensive review on thermodynamic aspect based solar desalination techniques. J Therm Anal Calorim 145(3):1103-1119

Wu SY, Zhong ZH, Xiao L, Chen ZL (2021) Performance analysis on a novel photovoltaic-hydrophilic modified tubular seawater desalination (PV-HMTSD) system. Desalination 499:114829 